\title{
Preface: Stem Cell Engineering for Regenerative Therapies
}

Mesenchymal stem cells (MSCs), a promising tool for regeneration therapies, have gained acceptance in designing novel therapeutic approaches for diseases such as osteoporosis, hepatic encephalopathy, diabetes, and many others.

The current issue of Critical Reviews ${ }^{\mathrm{TM}}$ in Biomedical Engineering examines research in four specific areas of stem cell engineering and regenerative medicine, reviewing the use of tissues from multiple sources within the human body. The multipotential differentiation ability of these cells makes them a promising tool for cell-based therapy.

Human Umbilical Cord-derived Stem Cells: Isolation, Characterization, Differentiation, and their Application in Treating Diabetes, by Drs. Chandravanshi and Bhonde, highlights research on islet regeneration for therapeutic applications in diabetes. ${ }^{1}$ The nonimmunogenic and nonimmunosuppressive properties of umbilical cord stem cells (UCMSCs), along with their ability to escalate vascularization, offer enormous potential for treatment of insulin insensitivity. UCMSCs ameliorate hyperglycemia and reduce inflammation that is associated with diabetes.

Next-Generation Bioinspired Engineering for Applications in Liver Tissue Regeneration and Development of Bioartificial Liver, by Dr. Kadam's team, describes various methods for liver tissue regeneration, with a futuristic approach to overcome hurdles associated with liver tissue engineering. ${ }^{2} \mathrm{Be}-$ cause liver transplant is the only current therapeutic option available for patients suffering with hepatic encephalopathy, hepatorenal syndrome, or multiorgan failure, the development of easily available and cost-effective applications such as a liver-on-a-chip platform, bioprinted liver, and three-dimensional (3D) composite constructs could prove to be viable therapeutic approaches.

Mr. Dave and Dr. Tomar provide a review of various dental tissues that possess significant potential as a source of MSCs in Dental Tissue-Derived Mesenchymal Stem Cells: Applications in Tissue Engineering. ${ }^{3}$ In recent years, dental tissue includ- ing pulp, periodontal ligament, gingiva, and exfoliated teeth have gained popularity as a source of MSCs due to its ease of harvest, faster healing at donor site, and qualifying criteria of large cell yields in a short duration of time.

Mr. Desai et al., in Scaffold Free Spheroids Derived from Stem Cells for Tissue-Engineering Applications, ${ }^{4}$ discusses techniques of 3D spheroid cultures using stem cells for tissue-engineering applications. Spheroids provide a favorable environment for cell survival and cell-cell interactions, thus mimicking the in vivo niche of cells. Use of spheroids also minimizes the need for scaffolds that in turn reduces inflammation and toxicity responses associated with scaffold materials.

The emergence of 3D bioprinting is expected to advance the area of organ transplantation and its use in conjunction with cells that could lead to development of customized live grafts. It is hoped that these therapies would be available in clinical medicine to treat specific pathologies effectively and improve overall treatment efficacy.

Authors in this group have experience in multiple areas of stem cell engineering. Dr. Ramesh Bhonde, with 38 years of experience in this field, works on characterization and therapeutic applications of stem cells from different sources for the treatment of diabetes. His recent research has provided evidence that multiple injections of unfractionated bone marrow can reverse experimental diabetes in mice. ${ }^{5-9}$

Dr. Sachin Kadam is chief technology officer at Advancells, a good manufacturing practices- and International Organization for Standardization-certified facility that is engaged in research activities for the production of scaffolds for bioartificial organ production. His team has been actively involved in studying regenerative aspects of stem cells derived from a variety of sources including umbilical cord, breast milk, and placenta. ${ }^{10-13}$

Dr. Geetanjali Tomar is a member of the faculty at the Institute of Bioinformatics and Biotechnology, 
affiliated with Savitribai Phule Pune University, Pune, India. Her team researches applications of dental tissue-derived MSCs for bone tissue-engineering applications. The group has published findings supporting gingiva (gum tissue) to be a better source of MSCs than bone marrow. Her laboratory is working on synthesis and characterization of nanoparticles and biomaterial scaffolds for bone regeneration, to enhance the efficacy of existing treatments for osteoporosis. ${ }^{14,15}$

Dr. Sachin Mamidwar, founder of Orthogen LLC, Springfield Township, NJ, has more than 35 years of experience in the fields of orthopedic and dental biomaterials and medical devices. Dr. Mamidwar directed the development of a new line of dental implants incorporating laser micromachining to improve bone and soft tissue attachment.

\section{REFERENCES}

1. Chandravanshi B, Bhonde RR. Human umbilical cord derived stem cells: Isolation, characterization, differentiation, and their application in treating diabetes. Crit Rev Biomed Eng. 2018;46(5):399-412.

2. Kashte S, Maras JS, Kadam S. Next-generation bioinspired engineering for applications in liver tissue regeneration and development of bioartificial liver. Crit Rev Biomed Eng. 2018;46(5):413-427.

3. Dave JR, Tomar GB. Dental tissue-derived mesenchymal stem cells: Applications in tissue engineering. Crit Rev Biomed Eng. 2018;46(5):429-468.

4. Desai KU, Salve PM, Sapkal NB, Dave JR, Tomar GB. Scaffold free spheroids derived from stem cells for tissue engineering applications. Crit Rev Biomed Eng. 2018;46(5):469-493.

5. Shree N, Bhonde R. Conditioned media from adipose tissue-derived mesenchymal stem cells reverse insulin resistance in cellular models. J Cell Biochem. 2017;118:2037-43.

\section{Guest Editors:}

Geetanjali B. Tomar, Ph.D.

Institute of Bioinformatics and Biotechnology

Savitribai Phule Pune University

Pune, India

Ramesh R. Bhonde, Ph.D.

Dr. D.Y. Patil University

Pune, India
6. Malekfar A, Valli K, Kanafi M, Bhonde R. Isolation and characterization of human dental pulp stem cells from cryopreserved pulp tissues obtained from teeth with irreversible pulpitis. J Endod. 2016;42:76-81.

7. Chandravanshi $B$, Bhonde RR. Shielding engineered islets with mesenchymal stem cells enhances survival under hypoxia. J Cell Biochem. 2017 Sep;118(9):2672-83.

8. Singh H, Ganneru S, Malakapalli V, Chalasani M, Nappanveettil G, Bhonde R, Venkatesan V. Islet adaptation to obesity and insulin resistance in WNIN/GR-Ob rats. Islets. 2014;6(5-6):e998099

9. Teotia R, Kadam S, Singh A, Verma S, Bahulekar A, Kanetkar S, Bellare J. Islet encapsulated implantable composite hollow fiber membrane based device: A bioartificial pancreas. Mater Sci Eng. 2017;77:857-66.

10. Kadam S, Muthyala S, Nair P, Bhonde R. Human placenta-derived mesenchymal stem cells and islet-like cell clusters generated from these cells as a novel source for stem cell therapy in diabetes. Rev Diabet Stud. 2010; 7:168-82.

11. Kadam S, Tiwari S, Bhonde R. Simultaneous isolation of vascular endothelial cells and mesenchymal stem cells from the human umbilical cord. Vitr Cell Dev Biol Anim. 2009;45:23-7.

12. Patki S, Kadam S, Chandra V, Bhonde R. Human breast milk is a rich source of multipotent mesenchymal stem cells. Hum Cell. 2010;23:35-40.

13. Kadam S, Govindasamy V, Bhonde R. Methods in molecular biology. Springer: Clifton, NJ; 2012.

14. Tomar G, Srivastava R, Gupta N, Barhanpurkar A, Pote S, Jhaveri H, Mishra G, Wani M. Human gingiva-derived mesenchymal stem cells are superior to bone marrow-derived mesenchymal stem cells for cell therapy in regenerative medicine. Biochem Biophys Res Commun. 2010;393:377-83.

15. Dave J, Dewle A, Mhaske S, Phulpagar P, Mathe V, More S, Khan A, Murthy A, Datar S, Jog A, Page M, Tomar G. Hydroxyapatite nanorods loaded with parathyroid hormone (PTH) synergistically enhance the net formative effect of PTH anabolic therapy. Nanomed Nanotechnol Biol Med. 2019;15:218-30.

Sachin Mamidwar, M.B.B.S, Ph.D.

Founder, Orthogen LLC

Springfield Township, NJ 